\title{
Correction to: Energy Routing Challenges and Protocols in Energy Internet: A Survey
}

\author{
Sara Hebal ${ }^{2} \cdot$ Saad Harous ${ }^{1}$ [D $\cdot$ Djamila Mechta ${ }^{2}$
}

Published online: 6 July 2021

(c) The Korean Institute of Electrical Engineers 2021

\section{Correction to: \\ Journal of Electrical Engineering \& Technology https://doi.org/10.1007/s42835-021-00789-3}

Due to an unfortunate oversight during the copy editing process the authorship order has been given erroneously. It should read:

Sara Hebal, Saad Harous, Djamila Mechta.

The original article has been corrected.

Publisher's Note Springer Nature remains neutral with regard to jurisdictional claims in published maps and institutional affiliations.

The original article can be found online at https://doi.org/10.1007/ s42835-021-00789-3.

Saad Harous

harous@uaeu.ac.ae

Sara Hebal

sara.hebal@univ-setif.dz

Djamila Mechta

mechtadjamila@univ-setif.dz

1 College of Information Technology, United Arab Emirates University, 15551 Al AIn, United Arab Emirates

2 LRSD Laboratory, Computer Science Department, College of Sciences, FerhatABBAS Sétif 1 University, 19000 Sétif, Algeria 